\title{
Formação Humanista do Estudante de Medicina no Contexto da Geriatria Inserida na Saúde Integrada da Família
}

\author{
Dragalzew, Danielle Caiado de Castro; Carrijo, Laís Ferreira; Freitas, Maíra Thomé \\ de; Silva, Mirian Paiva; Pricinote, Sílvia Cristina M. N. \\ Centro Universitário Unievangélica — dani_dragalzew@hotmail.com
}

\begin{abstract}
INTRODUÇÃO: Mundo passa por processo de envelhecimento populacional. Reconhecer essa mudança e a necessidade dos orgãos públicos serem capazes de acompanha-lá é premissa essencial para se pensar na introdução da geriatria na graduação de medicina. OBJETIVOS: Objetiva-se relatar a experiência dos graduandos (quarto período) na geriatria inserida na disciplina de saúde coletiva, visando formação médica centrada na pessoa, em equipe e na comunidade onde o idoso insere-se. MÉTODOS: Utilizou-se metodologia de problematização; discussão de casos clínicos; aulas expositivas dialogadas com geriatria em um Hospital do Idoso com assuntos envolvendo transição epidemiológica, envelhecimento, semiologia, síndromes geriátricas; Técnica de Estimativa Rápida e Participativa com temática: atenção oncológica / prevenção de câncer, finitude da vida / cuidados paliativos, atenção à saúde do idoso fundamentada na Política Nacional de Saúde da Pessoa Idosa, violência, problemas de maior prevalência e assistência farmacêutica. RESULTADOS: a experiência ocorreu durante primeiro semestre de 2013 e demonstrou que a teoria permitiu maior compreensão da dimensão da prática vivenciada na UBSF. Resultando na realização de levantamento dos idosos / microárea com seus problemas prevalentes, planejamento da capacitação dos ACS em atenção oncológica na APS, pré-consulta do idoso (preenchimento da caderneta do idoso, avaliação nutricional e ações educativas), acompanhamento à consulta médica do idoso, produção de banners informativos e trabalhos científicos. CONCLUSÕES: Compreender processo de senescência viabilizou entender melhor grande parte do público que recorre às unidades. Disciplina alertou alunos de cuidados e atenção especiais de que idosos necessitam. Reverteu-se esse conhecimento em ações de promoção e prevenção de saúde aos idosos, buscando maior adesão às políticas existentes e possibilitou diagnosticar necessidades latentes que carecem de resguardo público (profissionais capacitados, meios diagnósticos e medicações apropriadas). Geriatria é complexa, demandaria maior disponibilidade de carga horária, entretanto associação entre disciplinas direciona-se para proposta eficaz de aproximação dos graduandos às necessidades de saúde dos idosos.
\end{abstract}

Dragalzew, Danielle Caiado de Castro; Carrijo, Laís Ferreira; Freitas, Maíra Thomé de; Silva, Mirian Paiva; Pricinote, Sílvia Cristina M. N.. Formação Humanista do Estudante de Medicina no Contexto da Geriatria Inserida na Saúde Integrada da Família. In: Anais do Congresso Internacional de Humanidades \& Humanização em Saúde [= Blucher Medical Proceedings, num.2, vol.1]. São Paulo: Editora Blucher, 2014. ISSN 2357-7282

DOI 10.5151/medpro-cihhs-10465 